Article

\title{
Study on the Suitability of Passive Energy in Public Institutions in China
}

\author{
Shui Yu*, He Liu, Lu Bai and Fuhong Han \\ School of Municipal and Environmental Engineering, Shenyang Jianzhu University, Shenyang 110168, China; \\ liuhe@stu.sjzu.edu.cn (H.L.); JJL@stu.sjzu.edu.cn (L.B.); Hanfuhong1995@stu.sjzu.edu.cn (F.H.) \\ * Correspondence: hj_yushui@sjzu.edu.cn; Tel.: +86-188-0248-3528
}

Received: 23 May 2019; Accepted: 19 June 2019; Published: 25 June 2019

\begin{abstract}
To solve the problem of the low utilization ratio of clean renewable energy in public institutions, the basic information of energy utilization in public institutions was investigated. The suitability of passive energy use in public institutions was studied. According to the basic information and evaluation index of passive energy utilization in public institutions, the suitability of different types of passive energy (solar and geothermal energy) was studied by combining the resource conditions in different climate zones and the characteristics of energy utilization in typical public institutions, and the suitability distribution map was formed. In terms of research methods, the CRITIC (Criteria Importance Though Intercrieria Correlation) method based on the characteristics of objective data, and the natural breakpoint method based on the structure of objective data, were selected. Based on the climatic zoning of the buildings, this study conducted a suitability zoning. Each climatic region of buildings was divided into three sub-regions, which were the passive energy suitability regions of public institutions in the climatic region of the buildings. Finally, all of the regions with the same suitability were partitioned in order to obtain the final results. The distribution map of suitability for the different types of public institution buildings in the different regions is creatively established, which provides the basis for the selection of passive energy technology application schemes for public institution buildings in different regions, and provides macro guidance for energy planners and scheme designers.
\end{abstract}

Keywords: public institution; passive energy; CRITIC method

\section{Background}

After more than ten years of development, with the gradual attention of the state to the energy conservation work of public institutions, public institutions in various places have carried out many explorations in their own energy management and have achieved certain results [1-7] The relevant systems research and construction have been carried out throughout the country [8]. Some provinces and cities have introduced local approaches and supporting policies. In Beijing, solar hot water systems are mandatory in new homes. In Fujian, measures have been taken to strengthen the promotion, application, and management of renewable energy in civil buildings. Guangdong has incorporated green building management requirements into legislation. Some provinces and cities have carried out energy consumption data statistics, energy audits, or publicity for some public institutions. At the same time, however, there are also some problems that restrict the continuous promotion of the establishment of energy-saving institutions, and have not yet played a role in social demonstration.

In 2017 , China accounted for $23.2 \%$ of the global energy consumption and $33.6 \%$ of the global energy consumption growth. China has led the world in energy growth for 17 consecutive years. In 2017, China's natural gas consumption increased by $15 \%$, accounting for $32.6 \%$ of the net increase in global natural gas consumption. Coal accounted for $60.4 \%$ of China's energy mix in 2017, down from 
the $73.6 \%$ of a decade earlier and the $62.0 \%$ of 2016 [9]. The five-year plan is an important part of China's national economic plan, as well as its long-term plan. It mainly anticipates major national construction projects, the distribution of productive forces, and a significant proportion of the national economy, and sets goals and directions for the long-term development of the national economy. The outline of the 12th Five-Year Plan for the National Economic and Social Development of the People's Republic of China (2011-2015) is referred to as the 12th Five-Year Plan. The energy consumption structure of public institutions in the 12th Five-Year Plan is as follows: electricity accounts for $45.37 \%$, raw coal $30.86 \%$, and other $23.77 \%$. Compared with 2010, the proportion of electricity increased by 11.07 percentage points, while that of raw coal decreased by 17.16 percentage points. Compared with 2012, the per capita energy consumption of the national public institutions decreased by $15.21 \%$ in 2017 , and the energy consumption per unit of building area decreased by $12.39 \%$. The average energy consumption decreased by $12.85 \%$ in 2016 , and the energy consumption of construction area decreased by $10.17 \%$. Compared with 2008, the energy consumption per unit building area of public institutions decreased by $22.9 \%$ in 2017 , and the per capita energy consumption decreased by $29.4 \%$.

However, as of the 12th Five-Year Plan, China's total building energy consumption was 857 million tons of standard coal, accounting for $20 \%$ of the country's total energy consumption. The total energy consumption of public institutions is 183 million tons of standard coal, accounting for $21.35 \%$ of the total energy consumption of buildings in China, and $4.26 \%$ of the total energy consumption of the whole society. The per capita comprehensive energy consumption is $370.73 \mathrm{~kg}$ of standard coal per person, and the energy consumption per unit building area is $20.55 \mathrm{~kg}$ of standard coal per square meter. The energy consumption per unit area of urban residential buildings is $12.90 \mathrm{~kg}$ of standard coal per square meter, and that of the rural residential buildings is $7.82 \mathrm{~kg}$ of standard coal per square meter. The energy consumption per unit floor area of public institutions is 1.60 times that of urban residential buildings, and 2.63 times that of rural residential buildings [10].

Donglin Zhang, of Chongqing University, points out that the government's focus on energy efficiency in office buildings is to reduce the use of electricity and increase the use of renewable energy [11]. The energy intensity of office buildings of state organs in China is high, which is an abnormal situation. Meanwhile, with the development of residential buildings to high-rise and super-high-rise buildings in recent years, the energy consumption of power facilities has increased significantly, while the utilization rate of solar energy has decreased significantly, leading to the increase of energy intensity of such buildings [12]. Moreover, the utilization rate of clean renewable energy in universities and hospitals is low [13].

To sum up, public institutions are not only an important subject of energy consumption, but also an important field of energy conservation. This study explores and studies the current status, existing problems, and causes of passive energy applications, and promotes the use of passive energy sources in public institutions in China. In view of the current low utilization rate of clean renewable energy in public institutions, the basic information and research about the energy utilization of public institutions was carried out in order to study the suitability of passive energy utilization in public institutions, and to creatively establish the buildings suitable for different regions and different types of public institutions. The suitability map provides the basis for the selection of passive energy technology application schemes for public buildings in situations in different regions, providing macro guidance for energy planning and solution designers.

\section{Content}

Passive energy: For buildings, renewable energy that can be used in large quantities is a passive energy source. Renewable energy is inexhaustible, but not all renewable energy can be used for buildings. So, renewable energy includes passive energy, and solar energy, geothermal energy, and wind energy are all passive energy sources. The passive energy sources in the study are solar energy and geothermal energy. Active energy: For buildings, non-renewable energy, secondary energy, and 
renewable energy that cannot be used in large quantities are active energy sources, such as natural gas (non-renewable energy) and electric energy (secondary energy).

China is located in the eastern part of Eurasia in the Northern Hemisphere, mainly in the temperate zone and subtropical zone, with relatively abundant solar energy resources. According to the long-term observation data accumulated by more than 700 meteorological stations nationwide, the annual total solar radiation in China is roughly between $3.35 \times 103 \mathrm{MJ} / \mathrm{m}^{2}$ and $8.40 \times 103 \mathrm{MJ} / \mathrm{m}^{2}$, with an average value of about $5.86 \times 103 \mathrm{MJ} / \mathrm{m}^{2}$. China is rich in geothermal resources [14]. More than 2700 geothermal outcrops have been discovered. Most provinces (districts) in China have different geothermal outcrops, and there are many hotspots in Yunnan-345 places in Tibet, 342 places in Tibet, 320 places in Hebei, 295 places in Sichuan, and 229 in Guangdong, and so on. Most of the geothermal resources in China are in the low temperatures and have hot water, and there are only 600 hot spots above $80^{\circ} \mathrm{C}$. From the perspective of geothermal distribution in China, there is a trend of increasing geothermal quantity and increasing water temperature from the central to the eastern continental margin and the southwest. According to the survey and evaluation results of the China Geological Survey of the Ministry of Land and Resources, the amount of shallow geothermal energy resources in the cities above the prefecture level is equivalent to $95 \times 108 \mathrm{t}$ of standard coal, and the annual recoverable resources are equivalent to $7 \times 108 \mathrm{t}$ of standard coal. China has many types of geothermal resources, a wide distribution, large reserves, and great potential for development and utilization.

In view of the lack of basic data for passive energy applications in public institutions and the underutilization of passive energy sources, the scope and objectives of the research are first determined. The utilization of solar energy in public institutions mainly includes photothermal conversion, photovoltaic power generation, and solar lighting, and the utilization of geothermal energy in public institutions mainly includes underground water source heat pumps and soil source heat pumps. The main types of public institutions are government agencies (mainly office buildings) and educational buildings (for teaching in universities). In the three aspects of building and health-related buildings (mainly in outpatient and inpatient buildings), passive energy mainly considers solar energy and shallow geothermal energy. The utilization of solar energy is photothermal conversion, and the utilization of geothermal energy is shallow geothermal energy.

Public institutions were referred to as "government agencies" in early comprehensive policy documents. Among the ten key energy-saving projects in the "11th Five-Year Plan", the "Government Institutions Energy Conservation Project" defines government agencies as government agencies, institutions, and social organizations at all levels, including the military, armed police, education, public services, and so on. Government agencies include party organs, people's organs, administrative organs, Chinese People's Political Consultative Conference organs, judicial organs, procuratorial organs, and other public institutions, such as those directly under the state organs, and receiving all or part of financial funds for education, science and technology, culture, health, sports, and other related public welfare industries. Business unit organizations include social groups and related organizations such as workers, youth, and women who use financial funds in whole or in part. In the Regulations on Energy Conservation of Public Institutions promulgated in October 2008, public institutions are defined as state organs, institutions, and organizations that use financial funds in total or in part [15].

\subsection{Government Buildings}

Government buildings are public buildings constructed by central or local governments at all levels through financial allocation or administrative financing, and they are exclusively used by government departments at all levels. Government office buildings are mainly used for public management affairs and public services. The social functions they carry are necessary for social and economic development. The distribution of building energy consumption aims to meet the reasonable-use functions of buildings [11]. (1) Functional features of government office buildings: (a) Office space, including the leadership office and the general staff office. (b) Public service rooms, including conference rooms, reception rooms, printing rooms, archives, information centers, mailrooms, 
guard rooms, toilets, and so on. (c) Equipment room, including refrigeration machine room, variable pressure pump room, elevator machine room, power distribution room, and so on. (d) Auxiliary rooms, including canteens, fire rooms, garages, and so on. (2) Government building features: Government buildings are mostly multi-story buildings with sloping roofs or high-rise buildings with flat roofs. Limited by decoration and energy-saving standards, few government office buildings are equipped with glass curtain walls. The exterior is solemn and there is no balcony [16].

The factors affecting the energy consumption of government office buildings are as follows: (1) Construction scale. Buildings larger than $20,000 \mathrm{~m}^{2}$ are classified as large government buildings, otherwise, they are classified as non-large government buildings. According to the survey and analysis, in non-large government office buildings, the energy consumption generally decreases with the increase in the building scale, but it shows a smooth trend in a certain interval. In general, the energy consumption per unit area of large government office buildings is much lower than that of non-large government office buildings, as shown in Figures 1 and 2.

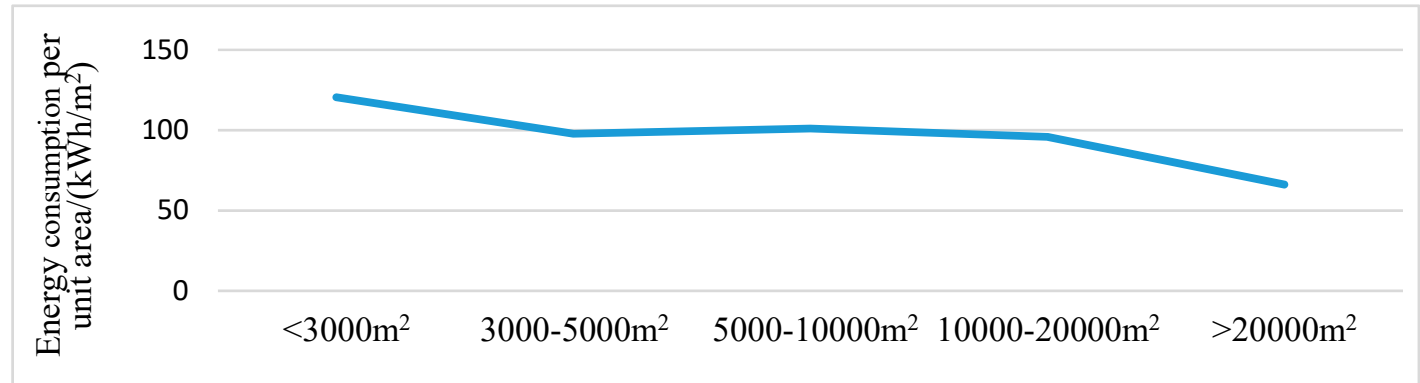

Figure 1. Relationship between the scale and energy consumption of non-large government office buildings.

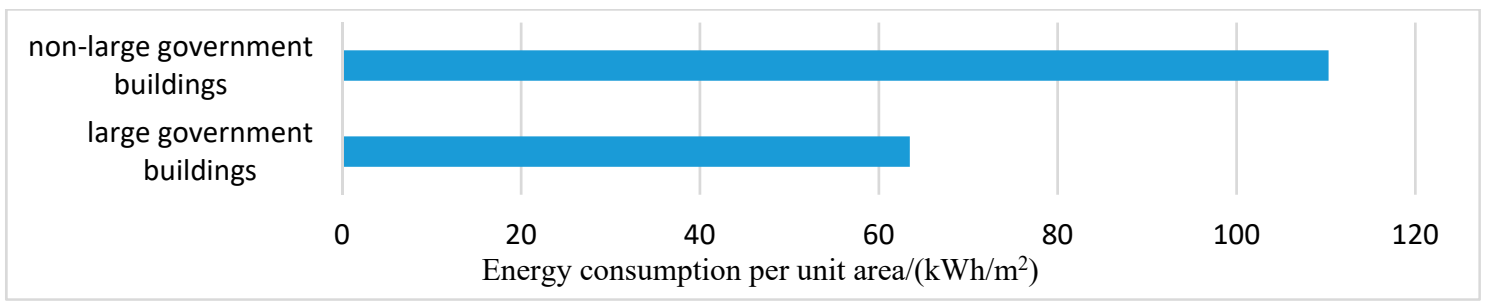

Figure 2. Energy consumption map of different building areas of government office buildings.

(2) Air conditioning form. The survey found that the energy consumption of government office buildings is easily affected by personnel behavior and load rate [17]. Therefore, although the central air conditioning system is superior to the non-central air conditioner in the performance of a single unit, the application process is not for a central air conditioning system to save energy and the central air conditioning system [11], as shown in Figure 3.

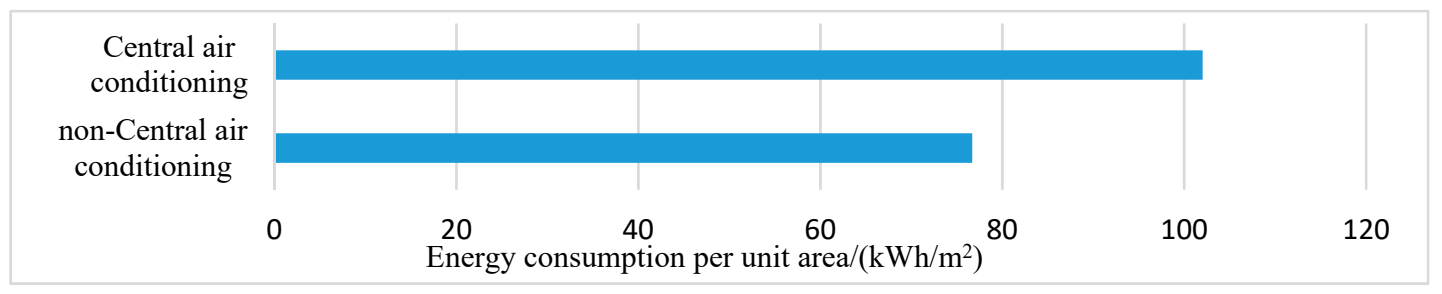

Figure 3. Energy consumption per unit area of different air conditioning forms in government office buildings. 


\subsection{University Building}

A university building is not a building, but a building group that contains many types of buildings. The functions of various buildings are not identical. The main types of college buildings are as follows: (a) Laboratory building. Most of the equipment used in the experimental building is mostly used during the day, and its energy consumption is closely related to various professions. Therefore, the energy consumption of the experimental building is significantly related to the type of colleges and universities. (b) Administrative building. The administrative building is mainly an office space. The density of the energy consumption is related to the working hours. The energy consumption is related to its scale. The site has high requirements for environmental comfort. The air conditioning energy consumption is large in summer, and the energy consumption of indoor office equipment is relatively fixed. The frequency of use of power equipment, such as elevators, is high during commuting hours. (c) Teaching building. The teaching building is a place for students to study and attend classes. As a result of the concentration of personnel, the main energy-consuming equipment in winter is certain lighting fixtures and multimedia. In summer, the air-conditioning energy consumption is too large, and the utilization rate of night classrooms affects the total energy consumption of such buildings.

From what has been discussed above, the sum of the energy consumption of different functional buildings in colleges and universities constitutes the total energy consumption of campus buildings. The energy consumption of public buildings in colleges and universities is related to many factors, such as the climate zone in which universities are located, as well as the types of colleges and universities. However, each university building group includes seven categories, namely: laboratory buildings, administrative buildings, teaching buildings, gymnasiums, libraries, dormitories, and restaurants. Common public buildings (because dormitories and canteens are gradually contracted by enterprises, so they are not in the scope of public institutions): the energy consumption of these buildings accounts for a large proportion of the total energy consumption of the campus [18], and the research is mainly based on teaching buildings.

\subsection{Hospital Building}

The outpatient department is the first place to contact the patient. The patient and family members must come to the hospital first to register in the clinic, and then will distribute to the various parts of the hospital. Therefore, the outpatient building is the place with the highest population density. Hospital composition: According to the functional department, it can be divided into various outpatient departments, public departments, and medical technology departments. The outpatient department includes the departments of internal medicine, surgery, pediatrics, office, treatment room, and so on. The public department includes the registration office, the toll collection office, the checkout office, and the medicine taking office, and the medical technology department includes the laboratory and the X-ray inspection room. Characteristics: (1) The flow density is large, and the stagnation time is extremely long. (2) The service target is a special group, so the air environment quality in the ward is very high. (3) The air conditioning system is a seasonal air conditioning system. (4) There is a certain pressure difference between the inside of the clinic and the corridor, so as to maintain the positive pressure in the room [19]. (5) Seasonal characteristics: The survey found that the seasonal characteristics of hospital energy consumption are significant. The hospital's electricity consumption is different in different months. Electricity peaks occur in July-September, while other seasons use less electricity, as shown in Figure 4. (6) Regional characteristics: Because the number of hospitals and climate characteristics are different in different regions, the energy consumption varies greatly, as shown in Figure 5 [20]. 


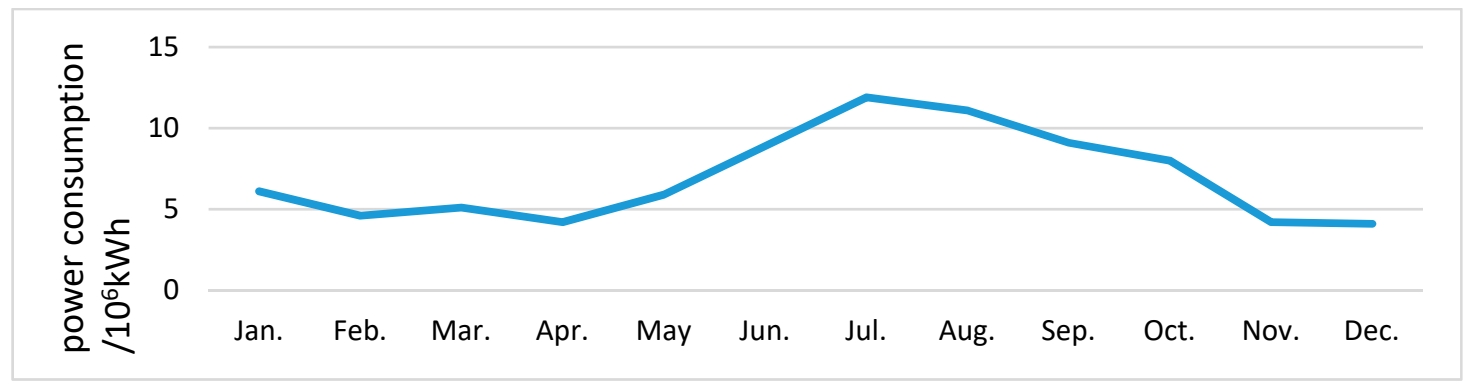

Figure 4. Monthly power consumption-change chart of a large hospital.

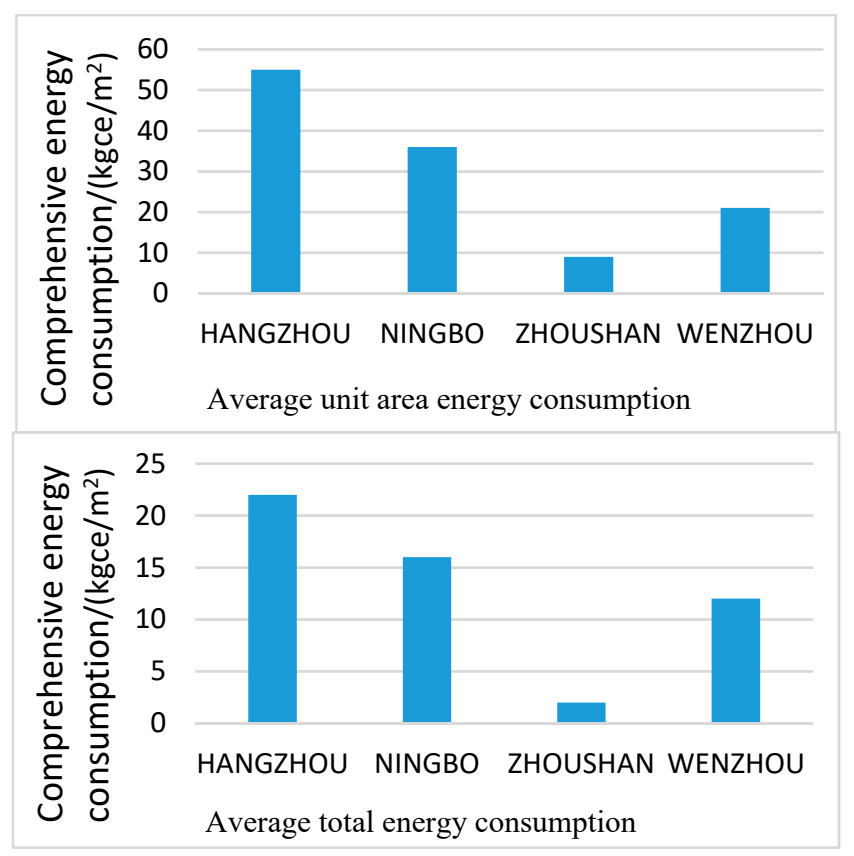

Figure 5. Comparison of the average energy consumption and average energy consumption of the average unit building area in each city.

\section{Methods}

Currently, the main method of suitability research is an indicator using the weight method, and currently, the method of determining the weight can be divided into the subjective weight method, the objective weight method, and the main objective weight method. The subjective weighting method is a kind of method in which researchers assign weights to each index according to their subjective value judgment. This kind of method is divided into the expert evaluation method, analytic hierarchy process, and so on. The weight of each index depends on the knowledge structure and personal preference of each expert. Although this is a good reflection of the subjective will, it lacks scientific stability. Considering its obvious defects, it is generally only applicable to the evaluation of data collection difficulties and information that cannot be accurately quantified. The objective weighting method is used to determine the weight according to the relationship between the original data, using a certain mathematical method. The judgment result does not depend on the subjective judgment of the person and has a strong mathematical theoretical basis [21]. Combination weighting method: Combining the results of subjective and objective weighting methods.

\subsection{Method Selection}

In the empowerment of the indicator system, the existing method of empowerment is both subjective and objective. Because this research is relatively pioneering, there are few domestic related 
researches. Therefore, the subjective empowerment method seems very weak. At this stage, the most widely used method of objective weighting is the entropy method [21-23].

Entropy was originally a thermodynamic concept. It was introduced by Claude Elwood Shannon to information theory, and it has been widely used in engineering, social, and economic fields [24-26]. In general, if the entropy of an index is smaller, the greater the degree of variation in the value of the target, the greater the amount of information, and the greater the role of the overall evaluation, the greater the amount of weight it has in the overall evaluation. On the contrary, the greater the entropy $\left(E_{j}\right)$ of certain indicators shows the smaller the degree of variation of its index value, the smaller the amount of information provided, the smaller the comprehensive evaluation of the role, and its weight should be smaller. The information entropy calculation formula of the indicator $j$ is as follows:

$$
E_{j}=-(\ln m)^{-1} \sum_{j=1}^{m} p_{i j} \cdot \ln p_{i j}
$$

where, $m$ is the number of objects to be evaluated, and $p_{i j}=\frac{d_{i j}}{\sum_{j=1}^{m} d_{i j}}$ if $p_{i j}=0$, we define the following:

$$
\lim _{p_{i j} \rightarrow 0} p_{i j} \cdot \ln p_{i j}=0
$$

Scope of application: (1) can be used to determine the weight of the indicators in any evaluation question, and (2) can be used to eliminate the indicators that contribute little to the evaluation results in the indicator system [22]. Advantages: Objectivity, relative to those subjective valuation methods, the accuracy is higher and the objectivity is stronger, which can better explain the results obtained. Adaptability can be used for any process that needs to determine the weight, and can also be used in combination with some methods. Disadvantages: only the influence of the index variation on the weight is considered, and the conflict between the indexes is not considered [23]. To sum up, in order to make up for the shortcomings of the entropy method, we have chosen the CRITIC (Criteria Importance Though Intercrieria Correlation) method as the method of empowerment in this study. Its basic idea is to determine the objective weight of the indicators based on two basic concepts. First, the contrast intensity, which represents the value difference between the different evaluation schemes of the same index, is expressed in the form of standard deviation, that is, the standard deviation difference indicates the value difference between the different schemes within the same index. The larger the standard deviation is, the greater the value difference between different schemes will be. The second is the conflict between the evaluation indicators. The conflict between the indicators is based on the correlation between indicators. For example, there is a strong positive correlation between two indicators, indicating that the conflict between two indicators is low. The first $j$ indicators and other indicators of the conflicting quantitative indicators are for $\sum_{i=1}^{n}\left(1-r_{t j}\right), r_{t j}$ is the correlation coefficient between evaluation index $t$ and evaluation index $j$, and $\sigma_{j}$ is the standard deviation of the index $j$. The determination of the objective weight of each index is a comprehensive measure of the comparative strength and conflict. If $n$ is the number of evaluation indicators, let $C_{j}$ denote the amount of information contained in the indicator $j$, then $C_{j}$ can be expressed as follows:

$$
C_{j}=\sigma_{j} \sum_{i=1}^{n}\left(1-r_{t j}\right)
$$


where, $\sigma_{j}$ is the standard deviation of the $j$ th index. The larger the $C_{j}$ is, the more information the indicator $j$ contains, and the greater the relative importance of the index is, so the objective weight $W_{j}$ of indicator $j$ should be as follows [27]:

$$
W_{j}=\frac{C_{j}}{\sum_{j=1}^{n} C_{j}}
$$

\subsection{Selection of Indicators}

The evaluation index of passive energy utilization of public institutions is determined. When the selection of the index is taken into consideration, it considers both the supply side and the demand side and covers the characteristics of public institutions and the characteristics of energy [28]. According to the basic information and evaluation indexes of the passive energy utilization of public institutions, combined with the resource conditions in different climate zones and the characteristics of the energy use of typical public institutions, the research on the suitability of different types of passive energy is conducted so as to form the suitability distribution map.

Considering the characteristics of public institutions and passive energy, from the perspective of the supply-side, the energy distribution in various regions is extremely important. The amount of energy in a region can reflect how much energy the region can provide to public institutions, which plays a major role in the suitability research index system. From a macro point of view, the application of technology is not considered. Therefore, technical indicators related to passive energy, such as average sunshine duration and hydrogeological factors, are not considered in this study. In addition, economic factors should also be considered. This study selects regional fixed asset investment. Because public institutions are funded by the government to complete construction projects, the selection of fixed asset investment can reflect the size of the government's investment in the construction of the area.

From the demand-side perspective, it is necessary to understand the building's energy use characteristics. From the perspective of the nature of building energy consumption characteristics, it can be seen from the existing building climate zoning map that the energy consumption characteristics of all kinds of buildings are the same in each partition. Therefore, in the research on the passive energy suitability of public institutions, this research is carried out based on the climate zoning map. From the perspective of building energy consumption characteristics, the energy consumption index of public institutions is basically the same, so the number of public institutions can be used to reflect the size of the energy consumption.

The mathematical explanation for this is as follows: assume that the five climate zones are I1, I2, I3, I4, and I5. According to the characteristics of the climate zone, the energy consumption characteristics of the buildings in each climate zone are the same. The suitability of renewable energy in buildings is influenced by factors such as building energy consumption. The main component of building energy consumption is the building load. Estimating the building load of the entire city can be calculated by the area thermal index method. Assume that the number of cities studied in the I1 climate zone is $m$. As the cities are all in the I1 climate zone, the area heat index $\left(a_{1}=a_{2}=\ldots=a_{m}\right)$ is the same, and the total area of the public institutions in the $k$ th city is $S_{k}$. Therefore, the total load of all of the public institutions in the $k$ th city is $F_{k}=a_{k} \times S_{k}$. In the later data processing, the most normalized method will be used, and the normalized data will be $F_{k^{\prime}}^{*} F_{k}^{*}=\frac{F_{k \max }^{*}-F_{k}}{F_{k \max }^{*}-F_{k \min }^{*}}=\frac{a_{k} S_{k \max }-a_{k} S_{k}}{a_{k} S_{k \max }-a_{k} S_{k \min }}=\frac{S_{k \max }-S_{k}}{S_{k \max }-S_{k \min }}$. Assuming that the number of public institutions is $n$ and the $\frac{S}{n}=\alpha$ of each province is the same, then $\frac{S_{k}}{n_{k}}=\alpha$ is the same. So, $F_{k}^{*}=\frac{S_{k \max }-S_{k}}{S_{k \max }-S_{k \min }}=\frac{\alpha n_{k \max }-\alpha n_{k}}{\alpha n_{k \max }-\alpha n_{k \min }}=\frac{n_{k \max }-n_{k}}{n_{k \max }-n_{k \min }}$. Thus, the main factor that ultimately affects energy consumption is the number of buildings.

In summary, this study conducted a suitability study on the basis of building a climate zoning map. The selected indexes were the average growth rate of the fixed asset investment, passive 
energy distribution in various regions, the number of public institutions, and energy consumption per unit area.

\section{Research Process}

In this study, the objective weighting method was used as the weighting method of the evaluation system, and the natural breakpoint method was used as the partitioning and data visualization method. Both of them are based on the characteristics of the data, excluding subjective factors to get the results, and they follow the scientific principle-the principle of objectivity, and the principle of feasibility by considering the characteristics of public institutions of passive energy suitability, in order to select the evaluation index. Then, the dirty data are removed by data features, and then the data are normalized. Secondly, the weight of the indicators is given, and the final score is obtained again. Finally, the natural breakpoint method was used to divide the country into 10 suitable areas (data visualization). In order to avoid subjective factors, CRITIC has made up the subjective disadvantages of the subjective empowerment law. This method has a strong objectivity and can indicate the degree of correlation (independence) between the indicators. At the same time, the natural breakpoint method is a statistical method for classification according to the objective data structure [29].

In the research on the passive energy suitability of public institutions, it is necessary to construct a corresponding evaluation system, which is generally required in order to give weight and score, and to find out the demarcation points for partitioning. Empowerment becomes the most important step. However, at the same time of empowerment, because of the great difference in the degree of data fluctuations, it is necessary to filter and eliminate the data, and then to conduct standardized processing. Therefore, the idea of this study is to screen and eliminate the data first, then carry out standardized processing, and finally carry out empowerment. In normalization, MMN (Min-max normalization) is a linear transformation of the original data, so that the resulting value maps are between (0-1) or some self-defined interval. The transformation function is as follows:

$$
\begin{aligned}
X^{*} & =\frac{X-X_{\min }}{X_{\max }-X_{\min }} \\
X^{*} & =\frac{X_{\max }-X}{X_{\max }-X_{\min }}
\end{aligned}
$$

If the larger play a superior role in the index evaluation system, Equation (5) is used, otherwise Equation (6). Where, $X_{\max }$ is the maximum value of the sample data and $X_{\min }$ is the minimum value of the sample data. The disadvantage of this method is that when there are individual dirty data, such as an attribute value that is too large or too small, it may lead to changes in $X_{\max }$ and $X_{\min }$, which in turn affects the processing of the entire data. At this time, only the greatest value normalization can be redefined. The extreme value has the exclusion of dirty data [22].

In mathematics, the difference of two orders of magnitude can be regarded as the infinity of the higher order ratio and the infinitesimal of the lower order ratio. Therefore, it is necessary to consider the fluctuation degree of data when selecting indicators, and to try to select the one with the fluctuation degree within two orders of magnitude. If it is not within two orders of magnitude, data filtering and elimination are required. It can be observed that in an indicator, the interval within two orders of magnitude is taken to cover most data, and the interval is $\left(a_{i}, b_{i}\right)$, where, $b_{i} / a_{i}<100$. Let $p_{i}$ be the data of the indicator. If $p_{i}>b_{i}$, the value takes 1 after normalization. If $p_{i}>a_{i}$, the value takes 0 after normalization. The calculation is shown in Tables 1-3. 
Table 1. Some provinces' and cities' geothermal energy data processing.

\begin{tabular}{cccc}
\hline Province & $\begin{array}{c}\text { Geothermal Energy } \\
{\left[\mathbf{M J} /\left({ }^{\circ} \mathbf{C} \times \mathbf{~ m}^{\mathbf{2}}\right)\right]}\end{array}$ & $\begin{array}{c}\text { Standardization } \\
\text { (Unchecked Dirty Data) }\end{array}$ & $\begin{array}{c}\text { Standardization } \\
\text { (Checked Dirty Data) }\end{array}$ \\
\hline Fujian & 157.73 & 0.01 & 0.19 \\
Gansu & 160.09 & 0.01 & 0.19 \\
Guangxi & 506.46 & 0.02 & 0.88 \\
Hainan & 565.13 & 0.03 & 1.00 \\
Jiangsu & 413.38 & 0.02 & 0.70 \\
Qinghai & 63.62 & 0.00 & 0.00 \\
Sichuan & 454.55 & 0.02 & 0.78 \\
Tianjin & 496.89 & 0.02 & 0.86 \\
Xinjiang & $18,764.20$ & 1.00 & 1.00 \\
Zhejiang & 532.76 & 0.03 & 0.94 \\
\hline
\end{tabular}

Note: The formula for the standardization of this indicator is Equation (5) [30]. Of a total of 31 sets of data, we selected 10 sets of data.

Table 2. The original data of each indicator of some provinces.

\begin{tabular}{cccc}
\hline Province & $\begin{array}{c}\text { Average Growth Rate of } \\
\text { Fixed Asset Investment }\end{array}$ & $\begin{array}{c}\text { Number of Public } \\
\text { Institutions }\end{array}$ & $\begin{array}{c}\text { Solar Energy Multi-Year } \\
\text { Average (0.01 MJ/m } \mathbf{2})\end{array}$ \\
\hline Fujian & 0.10 & 117,063 & 1.47 \\
Gansu & -0.20 & 69,259 & 1.46 \\
Guangxi & -0.40 & 86,813 & 1.68 \\
Hainan & 0.03 & 26,451 & 1.66 \\
Jiangsu & 0.11 & 127,608 & 1.38 \\
Qinghai & 0.14 & 41,668 & 1.61 \\
Sichuan & 0.16 & 103,631 & 1.03 \\
Tianjin & 0.19 & 15,678 & 1.57 \\
Xinjiang & -0.02 & 54,331 & 1.64 \\
Zhejiang & 0.11 & 44,668 & 1.22 \\
\hline
\end{tabular}

Table 3. The normalization of various indicators in some provinces and cities.

\begin{tabular}{ccccc}
\hline Province & $\begin{array}{c}\text { Average Growth Rate of } \\
\text { Fixed Asset Investment }\end{array}$ & $\begin{array}{c}\text { Number of Public } \\
\text { Institutions }\end{array}$ & $\begin{array}{c}\text { Geothermal } \\
\text { Energy }\end{array}$ & Solar Energy \\
\hline Fujian & 0.85 & 0.09 & 0.19 & 0.68 \\
Gansu & 0.34 & 0.52 & 0.19 & 0.66 \\
Guangxi & 0.00 & 0.36 & 0.88 & 1.00 \\
Hainan & 0.72 & 0.9 & 1.00 & 0.97 \\
Jiangsu & 0.86 & 0 & 0.70 & 0.54 \\
Qinghai & 0.91 & 0.77 & 0.00 & 0.89 \\
Sichuan & 0.95 & 0.21 & 0.78 & 0.00 \\
Tianjin & 1.00 & 1 & 0.86 & 0.83 \\
Xinjiang & 0.64 & 0.65 & 1.00 & 0.95 \\
Zhejiang & 0.85 & 0.74 & 0.94 & 0.30 \\
\hline
\end{tabular}

Note: As the quantity of public organizations are reflected by the energy consumption, and the lower the quantity of energy consumption, the formula for standardization selection is Equation (6).

As the number of public institutions can objectively reflect the local energy consumption, the amount of energy can objectively reflect the local passive energy supply. Therefore, the weight of these two indicators is large, as shown in Figure 6. 


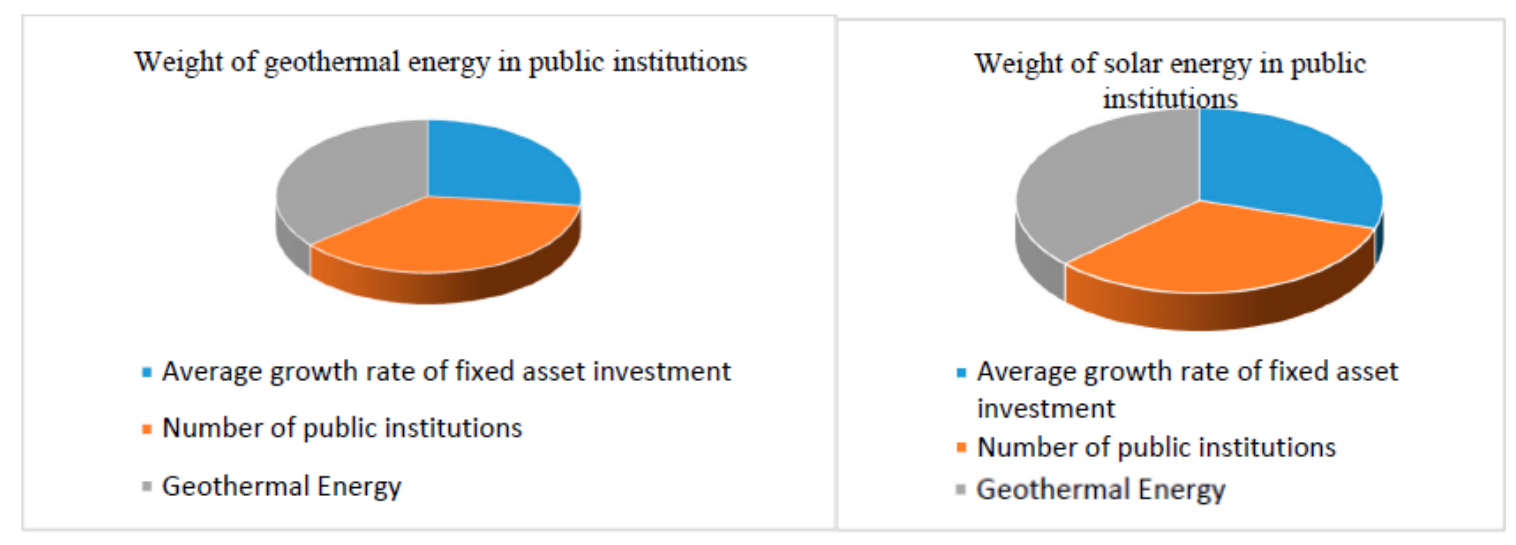

Figure 6. Weight diagram of passive energy for public institutions.

The final score for each region is as follows:

$$
F=W \cdot X^{*}
$$

The calculation results are as shown in Figure 7.

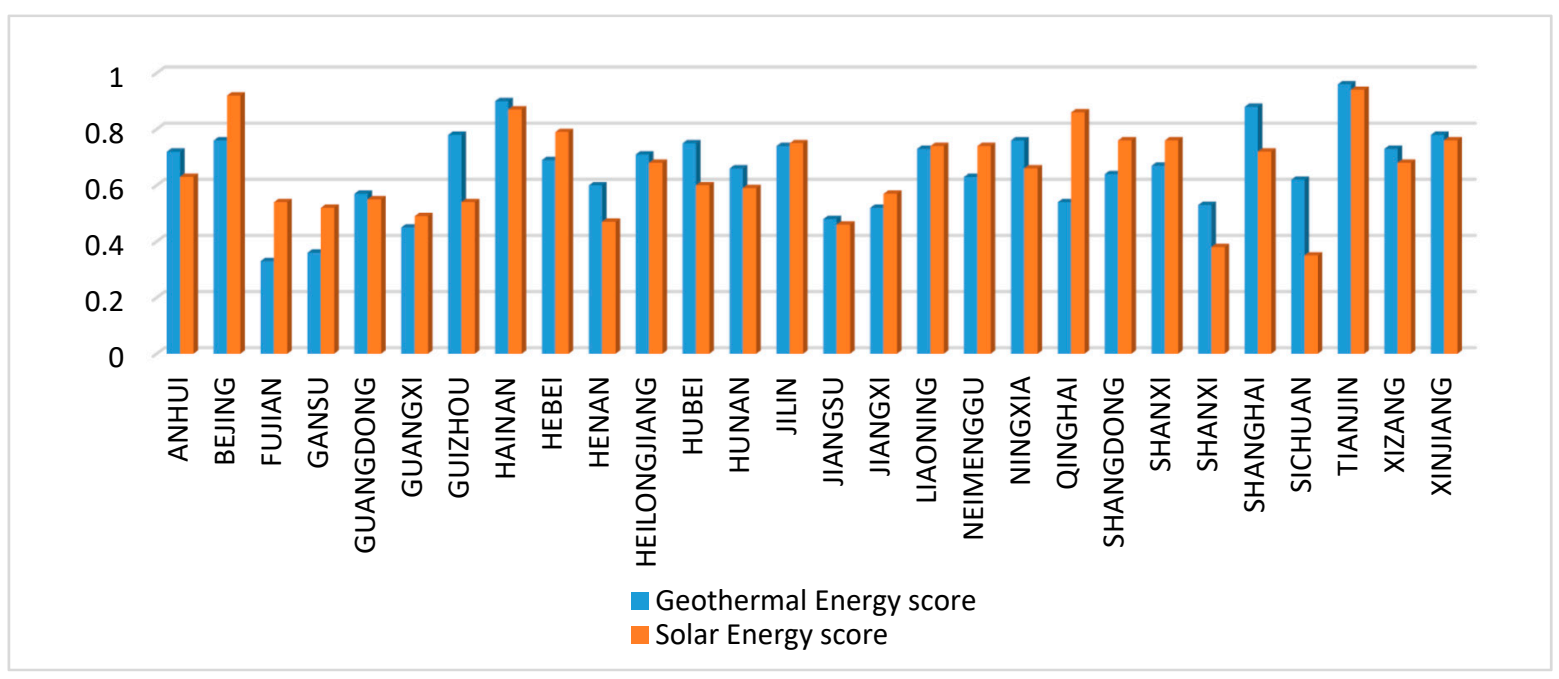

Figure 7. Public institution passive energy score map.

Finally, the data are partitioned and visualized in the form of a graph. The method used is the natural breakpoint method in ArcGIS. The natural breakpoint method is a statistical method that classifies according to the statistical distribution law, which can maximize the difference between classes. There are some natural turning points and feature points in any statistical series. With these points, the research objects can be divided into similar groups. Therefore, the crack itself is a good boundary for grading. Generating statistical data into frequency histograms, slope curves, and accumulated frequency histograms all help to find natural cracks in the data. This can be understood as follows:

1. The smallest difference within the class, the largest difference between classes

2. A map grading algorithm that considers that the data itself has a breakpoint and can be graded using the characteristics of the data.

3. The algorithm principle is a small cluster. The clustering end condition is that the variance between groups is the largest and the variance within the group is the smallest.

A suitability map was formed according to the above method. 


\section{Research Results and Analysis}

The passive energy suitability of public institutions is based on the characteristics of public institutions to conduct zoning research. Therefore, it is necessary to classify public institutions with the same architectural characteristics into a class of suitability research. Therefore, on the basis of building climate zoning, suitability zoning was carried out. Each building climate region was divided into three sub-regions (suitability region, general suitability region, and unsuitable region), which serve as the passive energy suitability region of public institutions in the building climate region. Then, the suitable areas, general suitable areas, and unsuitable areas of different climate zones were classified into passive energy suitability divisions of national public institutions, and then the appropriate areas, general suitable areas, and unsuitable areas of the country were divided into 10 different areas. The Figures 8-11 show the following: (1) the suitability map of passive energy use in public institutions was roughly the same as the trend of the energy distribution maps, that is to say, places with more passive energy sources are more suitable for public institutions. (2) The suitability map was based on the architectural climate map as a base map, so it contains the energy consumption characteristics of the building. From the details, the trend of the suitability map of passive energy use in public institutions was not exactly the same as the trend of energy distribution maps. (3) The development of buildings to the upper levels has led to a significant decline in the utilization of solar energy in government office buildings, but the solar energy in Yunnan is abundant, so government office buildings are more suitable for solar energy [12]. This conclusion is consistent with the distribution map I have drawn. (4) Taking Beijing as an example, Guanghui Xu evaluated the geothermal energy in Beijing, and listed a large number of engineering cases to prove the suitability of ground source heat pumps in public institutions in Beijing [31]. This conclusion is consistent with the distribution map I have drawn. The distribution map is shown in the Figures 8-11. The higher the level of appropriateness, the more appropriate, that is to say, the darker the color, the more appropriate.
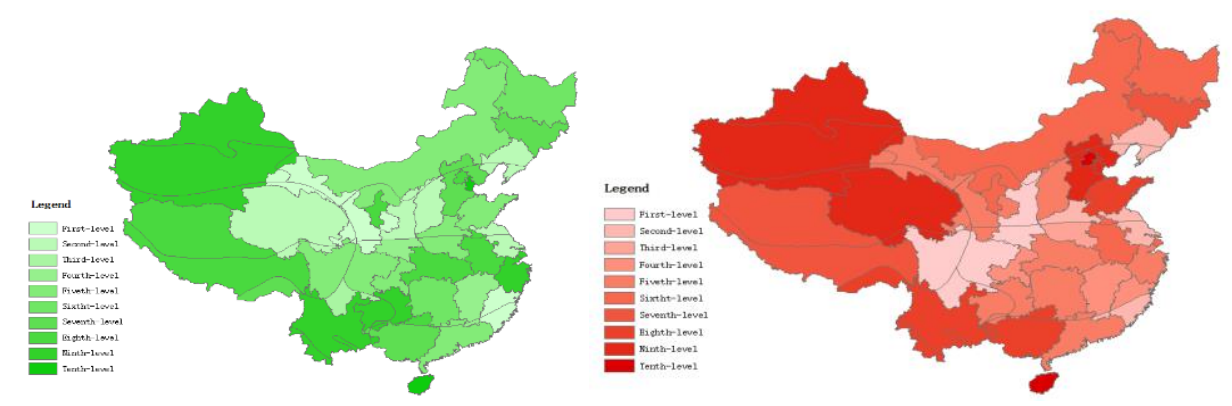

Figure 8. Distribution map of the geothermal energy (left) and solar energy (right) of the public institutions.
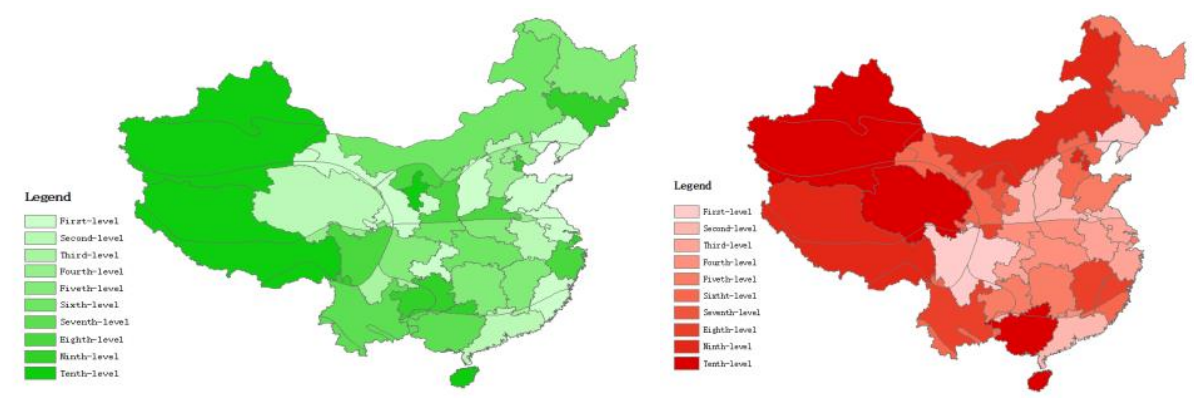

Figure 9. Distribution map of the geothermal energy (left) and solar energy (right) of schools. 

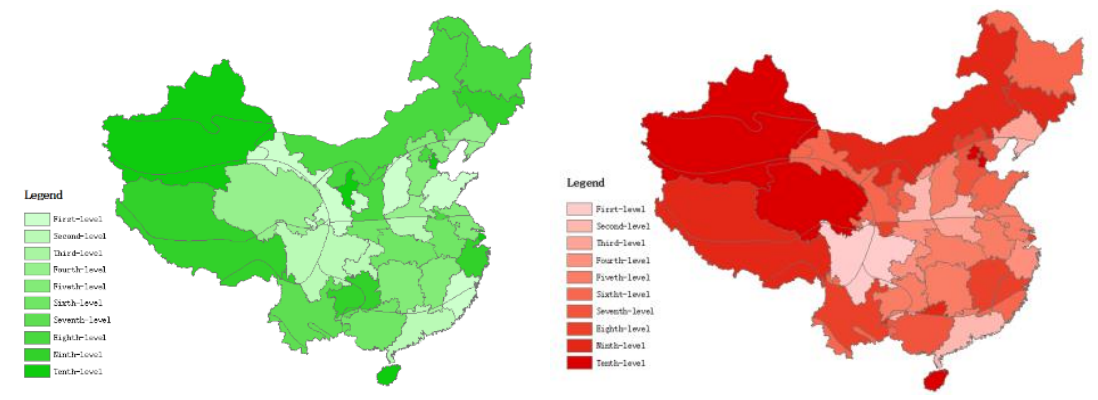

Figure 10. Distribution map of the geothermal energy (left) and solar energy (right) of government buildings.
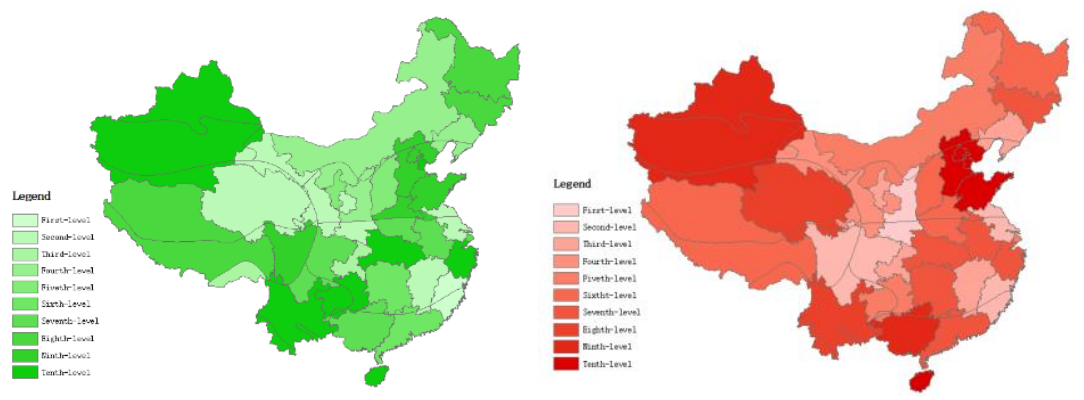

Figure 11. Distribution map of the geothermal energy (left) and solar energy (right) of hospitals.

Author Contributions: Conceptualization, S.Y. and H.L.; formal analysis, H.L.; funding acquisition, S.Y.; investigation, H.L., L.B., and F.H.; methodology, H.L.; project administration, S.Y.; resources, L.B.; writing (original draft), H.L.; writing (review and editing), H.L.

Funding: This research was funded by the National Key R\&D Program of China, grant number 2017YFC0702601; the Shenyang Young and Middle-Aged Science and Technology Innovation Talents Program, grant number RC170313; and the Liaoning Provincial Natural Foundation, grant number 20170540761.

Conflicts of Interest: The authors declare no conflict of interest.

\section{References}

1. Xu, Q. Research Status and Thinking of Energy Consumption Quota for Public Buildings. Build. Technol. 2010, 8, 35-37.

2. Xue, S.; Li, Y.; Ma, Y.; Yu, Y. Research on energy consumption quotas in universities in Hubei Province. Build. Sci. 2013, 29, 93-97.

3. Zhang, W. Energy-saving design and operation strategy of air-conditioning cold and heat source in Shanghai Fengxian Central Hospital. HVAC 2013, 43, 52-54.

4. Tang, P.; Ling, S.; Yang, Y.; Cui, Q.; Gong, Y. Measurement and Analysis of Buried Tube Heat Exchangers in Nanjing Area. Sol. Energy 2017, 38, 378-385.

5. Li, J.; Du, S.; Lai, Z. Application Test Analysis of Soil Source Heat Pump Air Conditioning System in Guiyang Area. Sichuan Build. Sci. Res. 2015, 41, 204-207.

6. Sun, W.; Zhou, N.; Huang, J.; Cai, W.; Wang, Y. Analysis of the variation characteristics of the geothermal field in the heat transfer zone of the ground source heat pump system. Acta Energ. Sin. 2017, 38, 2804-2810.

7. Hu, W.; Yan, D.; Liu, W. Study on the Guide to Energy Consumption Limits of Wuhan Civil Buildings. Build. Sci. 2015, 31, 42-47.

8. Lai, M. GB/T5116-2016, Energy Consumption Standard for Civil Buildings; Ministry of Housing and Urban-Rural Development of the People's Republic of China, China Building Industry Press: Beijing, China, 2016.

9. 2018 BP World Energy Statistical Yearbook. Available online: http://www.bp.com/en_US/china/ (accessed on 23 May 2019).

10. Hou, E. Release of the annual development research report on building energy conservation in China 2018. Build. Energy Conserv. 2008, 46, 133. 
11. Zhang, D.; Ding, Y.; Xie, L.; Kuang, Y. Investigation and analysis of energy consumption in government office buildings in chongqing. Civ. Eng. 2012, 34, 271-274.

12. Liu, Y.; Wu, D.; Li, H.; Lin, J.; Tang, L.; Cui, Y. Preliminary Analysis of Energy Consumption Statistics of Civil Buildings in Yunnan Province. HVAC 2016, 46, 6-11.

13. Long, W. Reflections on Building Energy Efficiency 2.0. HVAC 2016, 46, 1-12.

14. Yuan, X.; Gu, X.; Wang, J. Research Progress in Solar Energy Resource Assessment in China. J. Guizhou Meteorol. 2011, 35, 1-4.

15. Regulations on Energy Conservation in Public Institutions. Order of the State Council of the People's Republic of China. Available online: http://www.nea.gov.cn/2017-11/03/c_136725251.htm (accessed on 1 March 2019).

16. Chen, Y.; Wang, J.; Lin, W.; Fei, R.; Zhao, D. Study on the Suitability of Renewable Energy in Office Buildings in Zhejiang Province. Zhejiang Archit. 2016, 33, 50-54.

17. Libz, D. Part load operation coefficient of air-conditioning system of public building. Energy Build. 2010, 42, 1902-1907.

18. Liu, M. Research on Energy Consumption Prediction Model and Energy Conservation Management System of Public Buildings in Universities in Xi'an. Master's Thesis, Xi'an University of Architecture and Technology, Xi'an, China, 2017.

19. Guo, C. Research on Energy Saving Potential and Energy Saving Measures for Hospital Buildings. Master's Thesis, Hebei University of Engineering, Handan, China, 2018.

20. Lu, W.; Chang, Y.-X. Study on the Energy Consumption Survey of Hospitals in Zhejiang Province and Its Influencing Factors. Build. Sci. 2010, 26, 48-51, 107.

21. Baake, P.; Boom, A. Vertical Product Differentiation, Network Externalities, and Compatibility Decisions. Int. J. Ind. Organ. 2001, 19, 267-284. [CrossRef]

22. Zhang, S.; Zhang, M.; Chi, G. Science and Technology Evaluation Model and Empirical Study Based on Entropy Weight Method. Chin. J. Manag. 2010, 7, 34-42.

23. Wang, K.; Song, H. A Comparative Analysis of Three Objective Weighting Methods. J. Technol. Econ. Manag. 2003, 6, 48-49.

24. Wu, L.; Tan, Q.; Zhang, Y. Network connectivity entropy and its application on network connectivity reliability. Physics A 2013, 392, 5536-5541. [CrossRef]

25. Zou, Z.; Yun, Y.; Sun, J. Entropy method for determination of weight of evaluating indicators in fuzzy synthetic evaluation for water quality assessment. J. Environ. Sci. 2006, 18, 1020-1023. [CrossRef]

26. Liu, L.; Zhou, J.; An, X.; Zhang, Y.; Yang, L. Using fuzzy theory and information entropy for water quality assessment in Three Gorges region, China. Expert Syst. Appl. 2010, 37, 2517-2521. [CrossRef]

27. Diakoulaki, D.; Mavrolas, G.; Papayannakis, L. Determining objective weights in multiple criteria problems: The critic method. Comput. Oper. Res 1995, 22, 763-770. [CrossRef]

28. Long, W. Demand Side Energy Planning Adapts to Supply Side Structure Reform-Written in Front of "Urban Demand Side Energy Planning and Energy Microgrid Technology". HVAC 2016, 46, 135-138.

29. Wang, C. Evaluation of the Main Stream Resources in the Middle and Lower Reaches of the Yangtze River. Ph.D. Thesis, Graduate School of the Chinese Academy of Sciences (Nanjing Institute of Geography and Limnology), Nanjing, China, 2000.

30. Wang, G.; Zhang, W.; Liang, J.; Pei, W.; Liu, Z.; Wang, Y. Evaluation of geothermal resource potential in China. Chin. J. Earth 2017, 38, 449-450, 451-459, 584.

31. $\mathrm{Xu}, \mathrm{G}$. Demonstration Research on Shallow Geothermal Energy Resources Evaluation in Beijing. Ph.D. Thesis, China University of Geosciences (Beijing), Beijing, China, 2007.

(C) 2019 by the authors. Licensee MDPI, Basel, Switzerland. This article is an open access article distributed under the terms and conditions of the Creative Commons Attribution (CC BY) license (http://creativecommons.org/licenses/by/4.0/). 